Polymer Journal, Vol. 38, No. 10, pp. 1074-1080 (2006)

(C) 2006 The Society of Polymer Science, Japan

\title{
Synthesis and Properties of a Novel High Sensitive Photo-Radical Initiator Based on Biphenyl-2,2'-Dicarboximide Derivatives
}

\author{
Katsuya SAKAYORI, ${ }^{1, \dagger}$ Yuji SHIBASAKI, ${ }^{2}$ and Mitsuru UEDA ${ }^{2}$ \\ ${ }^{1}$ Material Research Laboratory, Nano Science Research Center, Dai Nippon Printing Co., Ltd., \\ 250-1, Wakashiba, Kashiwa 277-0871, Japan \\ ${ }^{2}$ Department of Organic and Polymeric Materials, Graduate School of Science and Engineering, \\ Tokyo Institute of Technology, 2-12-1-H120, O-okayama, Meguro-ku, Tokyo 152-8552, Japan
}

(Received May 2, 2006; Accepted July 29, 2006; Published September 15, 2006)

\begin{abstract}
A new high sensitive photo-radical initiator, $N$-[2-(2-acryloyloxyethoxy)ethyl]biphenyldicarboximide (BDI-5) was developed. BDI-5 was prepared from diphenic anhydride and aminoalcohol, followed by the reaction with acryloyl anhydride. BDI-5 is soluble in organic solvents, has no absorbance above $380 \mathrm{~nm}$ and high thermal stability over $300^{\circ} \mathrm{C}$. BDI-5 acts as a hydrogen transfer type photo-initiator in the presence of triethanolamine (TEA) as a proton donor, and has good compatibility with a matrix such as pentaerythritol triacrylate (PETA). The photosensitivity of BDI-5 with TEA for the polymerization of PETA was comparable to the excellent photo-radical initiators, 2-methyl-4'-(methylthio)-2-morpholinopropiophenone (Irg907). [doi:10.1295/polymj.PJ2006024]

KEY WORDS Biphenyldicarboximide / Photo-Radical Initiator / Photo Polymerization / UV Curable Resin / Thermal Properties /
\end{abstract}

Ultraviolet (UV) curing became very attractive buzzwords in the 1990s with the development of technologies, which are expanding rapidly on an industrial scale due to good productivity and low energy cureprocess. Among them, the plastics curable with photoradical initiators are the most important materials, and have been used as print inks, over-coatings of prints, protection coatings of printed-circuit boards (solder resist layer), and color filter resists of liquid crystalline display because of the low production costs and easy handlings. ${ }^{1,2}$

The photo-radical initiators are classified into two types: a self-cleavage and a hydrogen-transfer type compounds. The former compounds such as benzoin-ether generate radicals efficiently according to a Norrish I process, but the decomposed compounds during UV irradiation volatilize easily, and have odor. The latter compounds such as benzophenone abstract a proton from a donor to generate a radical. This type of photo-radical initiators does not decompose during the radical generation process, however, shows low photosensitivity compared to the former type photoradical initiators without a sensitizer, which induces coloration of clear coatings.

Jonsson et al. investigated three-component photoinitiators comprised of an $\mathrm{N}$-arylphthalimide, a diarylketone, and a tertiary amine, and concluded that an electron-proton transfer from an intermediate radical species to $\mathrm{N}$-arylphthalimide is responsible for gener- ating the initiating radicals. ${ }^{3}$

Very recently, we reported that a thermally stable naphthalimide derivative worked as a photo-radical initiator without a sensitizer and a proton donor, but its sensitivity and compatibility with acryl ester monomers were inferior to the conventional photoinitiator such as $\operatorname{Irg} 907 .^{4}$

Kubo et al. studied the intermolecular photoreaction of $N$-methylbiphenyl-2,2'-dicarboximide with 1,1-diphenylethylene in methanol, and reported that $\mathrm{N}$-methylbiphenyl-2,2'-dicarboximide played an important role for photochemical electron-transfer reactions. ${ }^{5,6}$

Biphenyl-2,2'-dicarboximide (BDI) is a strained seven-memberd cyclic imide, where the two benzene rings are twisted each other to keep the chemical structure. Thus, the imide carbonyl group will be an isolated carbonyl one, such as benzophenone, where $\mathrm{n}-\pi^{*}$ triplet states can abstract hydrogen from a proton donor. Moreover, its twisted structure will increase the solubility and compatibility with acryl ester monomers due to a low intermolecular interaction between BDI (Scheme 1). ${ }^{7}$ These beneficial features of BDI prompted us to develop a high sensitive photoinitiator with improved compatibility to various acrylates. This article reports the synthesis and properties of new highly sensitive photo-radical initiators on the basis of BDI moiety for clear coatings.

${ }^{\dagger}$ To whom correspondence should be addressed (Tel: +81-4-7134-1206, Fax: +81-4-7134-2821, E-mail: sakayori-k@mail.dnp.co.jp). 
A

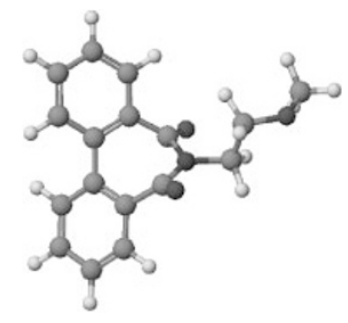

B
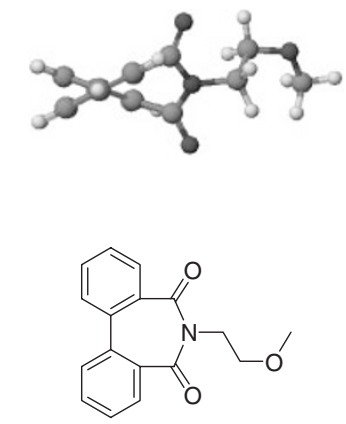

Scheme 1. PM5 calculated conformation of BDI. [(A: overhead view, B: side view) The PM5 calculation was carried out using MOPAC 2002, CAChe 6.1.12.33 (a Fujitsu group limited).]

\section{EXPERIMENTAL}

\section{Materials}

Acrylic anhydride was prepared by the reaction of sodium acrylate and acryloyl chloride. Pentaerythritol triacrylate (PETA) was obtained from Toagosei Co. Ltd. 2-Methyl-4'-(methylthio)-2-morpholinopropiophenone (Irg907) was purchased from Ciba Specialty Chemicals K.K, and used as received. Acrylic acid 2-(2-\{2-[2-(4-benzoyl-phenoxy)-ethoxy]-ethoxy\}-ethoxy)-ethyl ester (BPA) was purified by column chromatography of Ebecryl P36, which was purchased from Daicel UCB Co, Ltd. N-(2-methoxyethyl)-naphthalimide (NI) was prepared according to the literature. ${ }^{4}$ Other reagents and solvents were used as received.

Synthesis of N-(2-Methoxyethyl)-biphenyl-2,2'-dicarboximide (BDI-1)

Into a suspension of diphenic anhydride $(1.10 \mathrm{~g}$, $5.00 \mathrm{mmol}$ ) in $N, N$-dimethylformamide (DMF) (30 $\mathrm{mL})$ was added 2-methoxyethylamine $(0.380 \mathrm{~g}, 5.00$ $\mathrm{mmol}$ ) at room temperature. After $4 \mathrm{~h}$, acetic anhydride $(10 \mathrm{~mL})$ was added into the mixture, and the solution was stirred at $120^{\circ} \mathrm{C}$ for $5 \mathrm{~h}$. The resulting solution was poured into distilled water $(500 \mathrm{~mL})$ and the precipitate was collected, washed with distilled water, and dried in vacuo at $100^{\circ} \mathrm{C}$ for $2 \mathrm{~h}$, and recrystallized from ethanol to give white solids. The yield was $1.40 \mathrm{~g}$ (96\%): $\mathrm{mp} 106^{\circ} \mathrm{C}$ (by DTA). IR (Attenuated Total Reflection, v): $2930(\mathrm{C}-\mathrm{H}), 1698,1649$ and $1327(\mathrm{C}=\mathrm{O})$, $733 \mathrm{~cm}^{-1}$ (C-H: Ar). ${ }^{1} \mathrm{H}$ NMR $\left(\mathrm{CDCl}_{3}, \delta, \mathrm{ppm}\right): 7.84$ (d, $J=7.2 \mathrm{~Hz}, 2 \mathrm{H}, \mathrm{Ar}), 7.64$ (s, 2H, Ar), 7.63 (s, 2H, Ar), $7.50(\mathrm{~m}, 2 \mathrm{H}, \mathrm{Ar}), 4.43$ (t, $\left.2 \mathrm{H}, \mathrm{NCH}_{2} \mathrm{CH}_{2}\right), 3.67$ (t, $\left.2 \mathrm{H}, \mathrm{CH}_{2} \mathbf{C H}_{2} \mathrm{O}\right), 3.31$ (s, 3H, $\left.-\mathbf{C H}_{3}\right) .{ }^{13} \mathrm{C} \mathrm{NMR}$ $\left(\mathrm{CDCl}_{3}, \delta, \mathrm{ppm}\right): 46.38,58.58,70.68,128.44,128.49$, $131.03,131.90134 .85,135.00$, and 171.36. E $\mathrm{A}_{\mathrm{NAL}}$. Calcd for $\left(\mathrm{C}_{18} \mathrm{H}_{15} \mathrm{NO}_{4}\right): \mathrm{C}, 72.58 \% ; \mathrm{H}, 5.37 \%$; N, $4.98 \%$. Found: C, $72.15 \%$; H, 5.58\%; N, 4.58\%;

Synthesis of N-(2-Acetoxyethyl)-biphenyl-2,2'-dicarboximide (BDI-2)

This compound was prepared from diphenic anhydride $(1.10 \mathrm{~g}, 5.00 \mathrm{mmol})$ and 2-aminoethanol $(0.310 \mathrm{~g}, 5.00 \mathrm{mmol})$ as described above. The product was recrystallized from ethanol to give white solids. The yield was $1.40 \mathrm{~g}(92 \%)$ : mp $122^{\circ} \mathrm{C}$ (by DTA). IR (Attenuated Total Reflection, v): 2967 (C-H), $1743(\mathrm{C}=\mathrm{O}$ : aliphatic), 1693, 1649 and $1321(\mathrm{C}=\mathrm{O}$ : imide), 1230 (C-O-C: Acetyl), $737 \mathrm{~cm}^{-1}$ (C-H: Ar). ${ }^{1} \mathrm{H}$ NMR $\left(\mathrm{CDCl}_{3}, \delta, \mathrm{ppm}\right): 7.88(\mathrm{~d}, J=7.6 \mathrm{~Hz}, 2 \mathrm{H}$, Ar), 7.65 (s, 2H, Ar), 7.64 (s, 2H, Ar), 7.52 (m, 2H, Ar), 4.41 (s, 4H, NCH $\mathbf{C H}_{2}$ ), 2.01 (s, 3H, $-\mathrm{COCH}_{3}$ ). ${ }^{13} \mathrm{C}$ NMR $\left(\mathrm{CDCl}_{3}, \delta, \mathrm{ppm}\right): 20.90,45.91,62.48$, $128.62,128.73,131.16,132.25,134.59,135.03$, 170.73, and 171.36. $\mathrm{E}_{\mathrm{LEM}} \cdot \mathrm{A}_{\mathrm{NAL}}$. Calcd for $\left(\mathrm{C}_{18} \mathrm{H}_{15^{-}}\right.$ $\left.\mathrm{NO}_{4}\right): \mathrm{C}, 69.89 \% ; \mathrm{H}, 4.89 \%$;, $4.53 \%$. Found: $\mathrm{C}$, $69.99 \%$; H, 4.91\%; N, 4.08\%;

Synthesis of N-[2-(2-Acetoxyethoxy)ethyl]-biphenyl2,2'-dicarboximide (BDI-3)

This compound was prepared from diphenic anhydride $(1.10 \mathrm{~g}, 5.00 \mathrm{mmol})$ and 2-(2-aminoethoxy)ethanol $(0.530 \mathrm{~g}, 5.00 \mathrm{mmol})$ as described above. The product was recrystallized from ethanol to give white solids. The yield was $1.60 \mathrm{~g}(89 \%)$ : $\mathrm{mp} 51^{\circ} \mathrm{C}$ (by DTA). IR (Attenuated Total Reflection, v): 2872 (C-H), 1740 (C=O: aliphatic), 1692, 1647 and 1323 (C=O: imide), 1239 (C-O-C: Acetyl), $737 \mathrm{~cm}^{-1}$ (C-H: Ar). ${ }^{1} \mathrm{H}$ NMR $\left(\mathrm{CDCl}_{3}, \delta, \mathrm{ppm}\right): 7.85(\mathrm{~d}, J=$ $7.6 \mathrm{~Hz}, 2 \mathrm{H}, \mathrm{Ar}), 7.64$ (s, 2H, Ar), 7.63 (s, 2H, Ar), $7.50(\mathrm{~m}, 2 \mathrm{H}, \mathrm{Ar}), 4.34\left(\mathrm{t}, 2 \mathrm{H}, \mathrm{NCH}_{2} \mathrm{CH}_{2}\right), 4.13$ (t, $2 \mathrm{H}, \mathrm{OCH}_{2} \mathbf{C H}_{2} \mathrm{OCO}$ ), 3.78 (t, $2 \mathrm{H}, \mathrm{NCH}_{2} \mathbf{C H}_{2} \mathrm{O}$ ), 3.63 (t, $2 \mathrm{H}, \mathrm{OCH}_{2} \mathbf{C H}_{2} \mathrm{OCO}$ ), 2.03 (s, 3H, $-\mathrm{COCH}_{3}$ ). ${ }^{13} \mathrm{C} \mathrm{NMR}\left(\mathrm{CDCl}_{3}, \delta, \mathrm{ppm}\right): 20.86,46.40,63.66$, 68.60, 69.53, 128.49, 128.51, 131.06, 131.97, 134.83, 134.85, 170.93, and 171.23. E $\left(\mathrm{C}_{20} \mathrm{H}_{19} \mathrm{NO}_{5}\right): \mathrm{C}, 67.98 \%$; $\mathrm{H}, 5.42 \% ; \mathrm{N}, 3.96 \%$. Found: C, $68.39 \%$; H, 5.60\%; N, 3.65\%;

Synthesis of N-(2-Acryloylethyl)-biphenyl-2,2'-dicarboximide (BDI-4)

Acrylic anhydride was preliminarily prepared. Into a solution of acryloyl chloride $(4.50 \mathrm{~g}, 500 \mathrm{mmol})$ in diethyl ether $(30 \mathrm{~mL})$ was gently added sodium acrylate $(5.70 \mathrm{~g}, 600 \mathrm{mmol})$ at $0{ }^{\circ} \mathrm{C}$. The mixture was stirred at room temperature for $3 \mathrm{~h}$. The precipitate was 
filtered and the filtrate was concentrated under reduced pressure at $0^{\circ} \mathrm{C}$. The crude product was used for BDI synthesis without purification. Into a suspension of diphenic anhydride $(1.10 \mathrm{~g}, 5.00 \mathrm{mmol})$ in DMF $(30 \mathrm{~mL})$ was added 2-aminoethanol $(0.310 \mathrm{~g}$, $5.00 \mathrm{mmol})$. After stirring at room temperature for $4 \mathrm{~h}$, acrylic anhydride was added into the mixture, and stirred at room temperature for $5 \mathrm{~h}$. After washing with saturated $\mathrm{NaCO}_{3}$ aqueous solution, followed by brine, the product was extracted with $\mathrm{CHCl}_{3}$. The solvent was removed under reduced pressure, and the resulting material was purified by column chromatography (silica gel, $\mathrm{CHCl}_{3}$ :ethyl acetate $=20: 1$ ). The yield was $0.580 \mathrm{~g}(36 \%)$ : $\mathrm{mp} 108^{\circ} \mathrm{C}$ (by DTA). IR (Attenuated Total Reflection, v): 2973 (C-H), 1722 $(\mathrm{C}=\mathrm{O}$ : acryl $), 1695,1648$ and $1322(\mathrm{C}=\mathrm{O}$ : imide $)$, 1189 (C-O-C: acryl), 811 (C-H: vinyl) $737 \mathrm{~cm}^{-1}$ (C-H: Ar). ${ }^{1} \mathrm{H}$ NMR $\left(\mathrm{CDCl}_{3}, \delta, \mathrm{ppm}\right): 7.86(\mathrm{~d}, J=$ $8.0 \mathrm{~Hz}, 2 \mathrm{H}, \mathrm{Ar}), 7.64$ (s, 2H, Ar), 7.63 (s, 2H, Ar), $7.51(\mathrm{~m}, 2 \mathrm{H}, \mathrm{Ar}), 6.43\left[\mathrm{~d}, J=17.2,1 \mathrm{H}, \mathbf{C H}_{2}=\mathrm{CH}-\right.$ (CO-cis)], 6.08 [dd, $J=17.2,10.0,1 \mathrm{H}, \mathbf{C H}_{2}=\mathrm{CH}-$ (CO-trans) ], $5.84\left(\mathrm{~d}, J=10.0,1 \mathrm{H} \mathrm{CH}_{2}=\mathbf{C H}\right), 4.47(\mathrm{t}$, $2 \mathrm{H}, \mathrm{NCH}_{2} \mathrm{CH}_{2}$ ), 4.44 (t, $2 \mathrm{H}, \mathrm{CH}_{2} \mathbf{C H}_{2} \mathrm{O}$ ). ${ }^{13} \mathrm{C}$ NMR $\left(\mathrm{CDCl}_{3}, \delta, \mathrm{ppm}\right): 45.88,62.64,128.08,128.62$, $128.74,131.23,132.27,134.55,135.04,165.85$, and 171.15. $\mathrm{E}_{\text {LEM. }} \mathrm{A}_{\mathrm{NAL}}$. Calcd for $\left(\mathrm{C}_{19} \mathrm{H}_{15} \mathrm{NO}_{4}\right)$ : C, 71.02\%; H, 4.71\%; N, 4.36\%. Found: C, 71.53\%; H, $5.02 \% ; \mathrm{N}, 3.91 \%$;

Synthesis of N-[2-(2-Acryloylethoxy)ethyl]-biphenyl2,2'-dicarboximide (BDI-5)

This compound was prepared from diphenic anhydride $(1.10 \mathrm{~g}, 5.00 \mathrm{mmol})$ and 2-(2-aminoethoxy)ethanol $(0.530 \mathrm{~g}, 5.00 \mathrm{mmol})$ as described above. The product was purified by column chromatography (silica gel, $\mathrm{CHCl}_{3}$ ). The yield was $0.600 \mathrm{~g}(33 \%)$ : mp $51.4^{\circ} \mathrm{C}$ (by DTA). IR (Attenuated Total Reflection, v): $2895(\mathrm{C}-\mathrm{H}), 1724(\mathrm{C}=\mathrm{O}$ : acryl), 1703, 1646 and 1322 (C=O: imide), 1196 (C-O-C: acryl), 808 (C-H: vinyl) $737 \mathrm{~cm}^{-1}$ (C-H: Ar). ${ }^{1} \mathrm{H}$ NMR $\left(\mathrm{CDCl}_{3}, \delta, \mathrm{ppm}\right): 7.85$ (d, $\left.J=8.0 \mathrm{~Hz}, 2 \mathrm{H}, \mathrm{Ar}\right), 7.64$ (s, 2H, Ar), 7.63 (s, 2H, Ar), $7.50(\mathrm{~m}, 2 \mathrm{H}, \mathrm{Ar}), 6.40$ $\left[\mathrm{d}, J=17.6,1 \mathrm{H}, \quad \mathbf{C H}_{2}=\mathrm{CH}-(\mathrm{CO}-\right.$ cis $\left.)\right], 6.10[\mathrm{dd}$, $J=17.6,10.0,1 \mathrm{H}, \mathbf{C H}_{2}=\mathrm{CH}-(\mathrm{CO}-$ trans $\left.)\right], 5.84(\mathrm{~d}$, $\left.J=10.4,1 \mathrm{H} \mathrm{CH}_{2}=\mathbf{C H}\right), 4.35$ (t, $2 \mathrm{H}, \mathrm{NCH}_{2} \mathrm{CH}_{2} \mathrm{O}-$ ), 4.22 (t, $2 \mathrm{H},-\mathrm{OCH}_{2} \mathbf{C H}_{2} \mathrm{OCO}-$ ), 3.79 (t, $2 \mathrm{H},-\mathrm{NCH}_{2}-$ $\mathbf{C H}_{2} \mathrm{O}-$ ), 3.67 (t, $\left.2 \mathrm{H},-\mathrm{OCH}_{2} \mathrm{CH}_{2} \mathrm{OCO}-\right)$. ${ }^{13} \mathrm{C}$ NMR $\left(\mathrm{CDCl}_{3}, \delta, \mathrm{ppm}\right): 46.46,63.77,68.60,69.41,128.14$, $128.48,128.52,130.98,131.04,131.97,134.83$, 134.85, 166.05, and 171.26. $\mathrm{E}_{\mathrm{LEM}}$. $\mathrm{A}_{\mathrm{NAL}}$. Calcd for $\left(\mathrm{C}_{21} \mathrm{H}_{19} \mathrm{NO}_{5}\right)$ : C, 69.03\%; $\mathrm{H}, 5.24 \% ; \mathrm{N}, 3.83 \%$. Found: C, 69.08\%; H, 5.44\%; N, 3.47\%;

Synthesis of N-(2-Methoxyethyl)phthalimide (PI)

Into a suspension of pyromellitic anhydride
$(0.740 \mathrm{~g}, 5.00 \mathrm{mmol})$ in dry DMF $(30 \mathrm{~mL})$ was added 2-methoxyethylamine $(0.380 \mathrm{~g}, 5.00 \mathrm{mmol})$. After $4 \mathrm{~h}$, acetic anhydride $(10 \mathrm{~mL})$ was added into the mixture, stirred at $120^{\circ} \mathrm{C}$ for $5 \mathrm{~h}$, and poured into distilled water $(500 \mathrm{~mL})$. The precipitate was collected and dried in vacuo at $100^{\circ} \mathrm{C}$ for $2 \mathrm{~h}$. The product was recrystallized from ethanol. The yield was $0.960 \mathrm{~g}(75 \%)$ : $\mathrm{mp}$ $151^{\circ} \mathrm{C}$ (by DTA). IR (Attenuated Total Reflection, $v$ ): $2884(\mathrm{C}-\mathrm{H}), 1768,1704$ and $1398(\mathrm{C}=\mathrm{O}), 1117,1028$ and $731 \mathrm{~cm}^{-1}\left(\mathrm{C}-\mathrm{H}\right.$ : Ar). ${ }^{1} \mathrm{H} \mathrm{NMR}\left(\mathrm{CDCl}_{3}, \delta, \mathrm{ppm}\right)$ : $7.86(\mathrm{dd}, J=5.2,3.2 \mathrm{~Hz}, 2 \mathrm{H}, \mathrm{Ar}), 7.72(\mathrm{dd}, J=5.6$, $3.2 \mathrm{~Hz}, 2 \mathrm{H}, \mathrm{Ar}), 3.91$ (t, $2 \mathrm{H}, \mathrm{NCH}_{2} \mathrm{CH}_{2}$ ), 3.64 (t, $2 \mathrm{H}$, $\left.\mathrm{NCH}_{2} \mathbf{C H}_{2} \mathrm{O}\right), 3.35$ (s, $\left.3 \mathrm{H},-\mathbf{C H}_{3}\right) .{ }^{13} \mathrm{C}$ NMR $\left(\mathrm{CDCl}_{3}\right.$, $\delta$, ppm): 37.25, 58.57, 69.35, 123.20, 132.06, 133.85, and 168.24. $E_{\text {LEM. }} A_{N A L}$. Calcd for $\left(\mathrm{C}_{11} \mathrm{H}_{11} \mathrm{NO}_{3}\right)$ : C, $64.38 \%$; H, 5.40\%; N, 6.83\%. Found: C, 64.86\%; H, $5.56 \% ; \mathrm{N}, 6.78 \%$;

\section{Measurements}

Thermal analysis (TG-DTA) was performed on a RIGAKU TG8120 at a heating rate of $10^{\circ} \mathrm{C} / \mathrm{min}$ under nitrogen. ${ }^{1} \mathrm{H}$ NMR spectra were recorded on a JEOL JNM-LA400WB spectrometer. Samples were analyzed in $\mathrm{CDCl}_{3}$, and the chemical shift values were expressed relative to $\mathrm{Me}_{4} \mathrm{Si}$ as an internal standard. UV-visible spectra were obtained on a SHIMADZU UV-2550GLP spectrometer, and samples were analyzed in acetonitrile at $23^{\circ} \mathrm{C}$. Infrared spectra for identification were recorded on a JASCO FT-IR 610 infrared spectrophotometer using a SensIR Technologies Durascope diamond ATR unit, and samples were analyzed at $23^{\circ} \mathrm{C}$. The photosensitivity of BDIs in polymerizations was determined by UV-IR (Ultraviolet infrared spectroscopy). UV source was used USHIO USH-255BY without filtration, and an infrared spectra were recorded on a BIORAD FT-S6000 spectrometer in a nitrogen atmosphere.

\section{RESULTS AND DISCUSSION}

Synthesis of Photo-Radical Initiators (BDI-1-BDI-3)

BDI-1-BDI-3 were prepared by condensation of diphenic anhydride and primary amines followed by imidization. The amic acids were quantitatively converted into corresponding imides by chemical imidization using acetic anhydride in DMF at $120^{\circ} \mathrm{C}$ for $5 \mathrm{~h}$ (Scheme 2). In the case of using hydroxyamine as an amino moiety, the acylation of hydroxyl group proceeded with imidization.

The thermal imidization was not effective for BDI-1-BDI-3 because of the strained structure. Since the amide and carboxyl groups of amic acids for fiveor six membered cyclic imides place in a same plane, thermal imidization easily occurs. On the contrary, the two functional groups in BDI-1-BDI-3 don't place in 


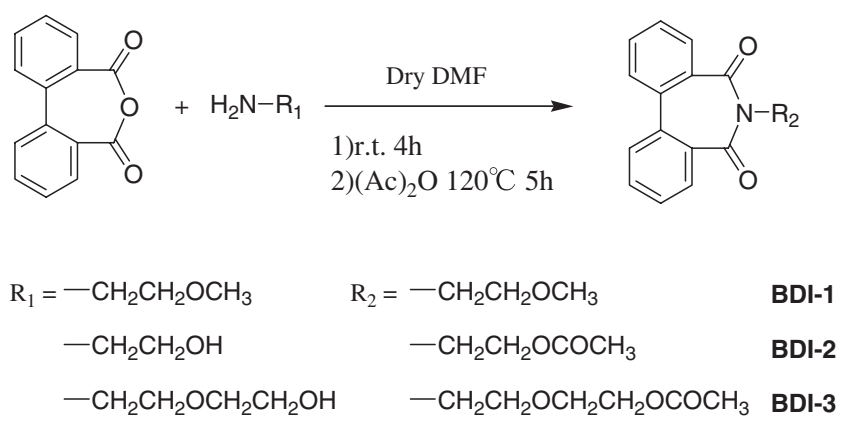

Scheme 2. Synthesis of BDI-1 BDI-3.

Table I. Thermal properties of BDI-1-BDI-3 and photoinitiators

\begin{tabular}{ccc}
\hline Photoinitiator & $\begin{array}{c}\text { Melting point } \\
\left({ }^{\circ} \mathrm{C}\right)\end{array}$ & $\begin{array}{c}\text { The temperature for } \\
5 \% \text { weight } \operatorname{loss}^{\mathrm{a}}\left({ }^{\circ} \mathrm{C}\right)\end{array}$ \\
\hline BDI-1 & 106 & 224 \\
BDI-2 & 123 & 240 \\
BDI-3 & 51 & 260 \\
& & \\
NI & 180 & 229 \\
BPA & $-{ }^{\mathrm{b}}$ & 157 \\
Irg907 & 77 & 207 \\
\hline
\end{tabular}

ain nitrogen from TG-DTA at a heating rate of $10^{\circ} \mathrm{C} / \mathrm{min}$, bliquid at $23^{\circ} \mathrm{C}$.

the same plane, the imidization requires the extra entropy of activation.

\section{Thermal Properties of BDI-1-BDI-3}

The thermal properties of BDI-1-BDI-3 were examined with TG-DTA. The results are summarized in Table I. The 5\% weight loss temperatures of BDI-1-BDI-3 were higher than those of the conventional hydrogen-transfer photo-radical initiators BPA and a typical self-cleavage photo-radical initiator Irg907, and were comparable to those of common imide compounds such as naphthalimide (NI) (Scheme 3). On the other hand, the melting points of BDI-1-BDI-3 were fairly lower than that of NI due to its non-plane structure, which reduces the intermolecular interaction of BDI-1-BDI-3.

\section{Solubility of BDI-1}

NI has photo-radical generating ability with good thermal stability, but it shows low compatibility to various acrylates. Therefore, in a film based on polyacrylates and NI, NI is apt to separate from the film, and the film becomes opaque. The low compatibility of NI to acrylates is attributed to the strong intermolecular $\pi-\pi$ interaction due to its large $\pi$-plane.

Since the compatibility is related to the solubility, the solubility of BDI-1 and NI was examined in various solvents and acrylates at a concentration of 0.5<smiles>COCCN1C(=O)c2ccccc2C1=O</smiles>

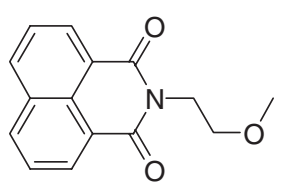

NI

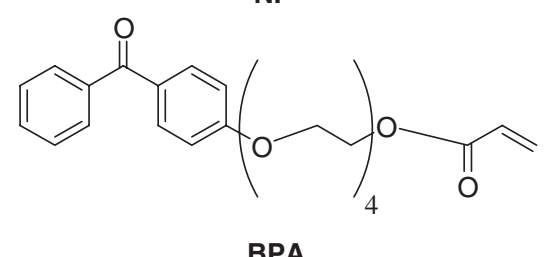

BPA

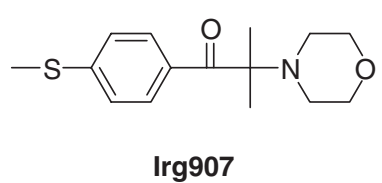

Scheme 3. Chemical structures of photoinitiators.

Table II. Solubilities of BDI-1 and NI

\begin{tabular}{ccc}
\hline & BDI-1 & NI \\
\hline $\mathrm{CHCl}_{3}$ & + & + \\
Acetone & + & + \\
DMF & + & + \\
THF & + & + \\
AcOEt & + & - \\
PGMEA & + & - \\
EL & + & - \\
MA & + & - \\
PETA & + & - \\
\hline
\end{tabular}

+: soluble, - : insoluble, determined in $0.5 \mathrm{~mol} / \mathrm{L}$ solution after treatment of ultrasonic at $23^{\circ} \mathrm{C}$ for $3 \mathrm{~h}$, THF: tetrahydrofuran, AcOEt: ethylacetate, PGMEA: propylene glycol monomethyl ether acetate, EL: ethyllactate, MA: methylacrylate, PETA: pentaerythritoltriacrylate.

$\mathrm{mol} / \mathrm{L}$, where sonication was applied at $23{ }^{\circ} \mathrm{C}$ for $3 \mathrm{~h}$. (Table II) BDI-1 showed high solubility in various organic solvents and acrylates compared to NI. This solubility behavior is also explained by the weak intermolecular $\pi-\pi$ interaction between BDI- 1 due to its twisted structure. BDI-2 and BDI-3 showed same solubility to that of BDI-1 due to the reason described above.

\section{UV Spectra of BDI-1}

Figure 1 shows the UV absorption spectra of BDI-1, PI and NI. The UV absorption spectra were measured at $1.0 \times 10^{-5} \mathrm{~mol} / \mathrm{L}$ in acetonitrile. BDI-1 


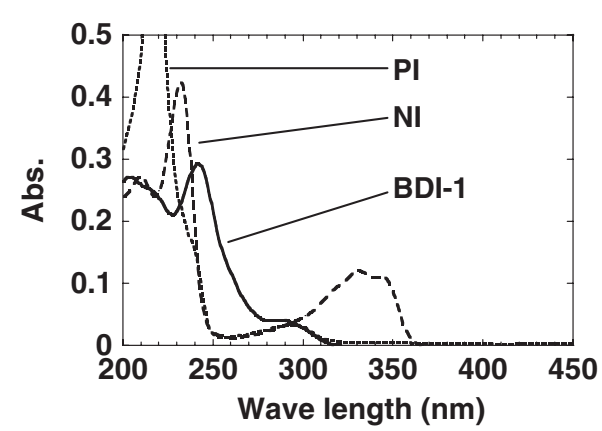

Figure 1. UV spectra of BDI-1, NI and PI in acetonitrile. $\left(1 \times 10^{-5} \mathrm{~mol} / \mathrm{L}\right)$

has a broad absorption in the range of $230-320 \mathrm{~nm}$. The $\varepsilon$ at $290 \mathrm{~nm}$ is $4.0 \times 10^{3}$. The UV-absorption of BDI-1 is blue-shifted compared to that of NI as a result of inhibition of $\pi$-conjugation between two benzene moieties due to the twisted structure.

\section{Photosensitivity of BDI-1-BDI-3}

The photosensitivity of BDI-1-BDI-3 for radical polymerizations was examined by UV-IR spectroscopy. The polymerization rate of PETA with BDI-1BDI-3 was determined with the decrease of the vinyl group in the acrylate group appeared at $810 \mathrm{~cm}^{-1}$. The molar feed ratio of PETA to BDI-1-BDI-3 was 17 to 1 , which means the molar ratio of vinyl group of PETA to BDI-1-BDI-3 was 50 to 1 . The film was spin-coated from the solution of PETA containing BDI-1-BDI-3 in $\mathrm{CHCl}_{3}$ on a chrome-plated glass surface, and the decrease of the vinyl group peak was followed by the reflection infrared spectroscopy in nitrogen atmosphere. As the vinyl group of PETA containing BDI-1-BDI-3 hardly decreased below the dose of $500 \mathrm{~mJ} / \mathrm{cm}^{2}$. As described above, the sevenmembered cyclic imide moiety of BDI-1-BDI-3 is not plane conformation, its carbonyl groups in the imide moiety are similar to a isolated carbonyl ones, whose $n-\pi^{*}$ triplet states have high ability to abstract hydrogen from a proton donor. Thus, an equimolar amount of triethanolamine (TEA) as the proton donor to BDI-1-BDI-3 was added. The results are shown in Figure 2. The vinyl group of PETA containing BDI-1-BDI-3 and TEA was rapidly consumed during UV-exposure. BDI-1-BDI-3 require the proton donor to generate radicals. In other words, they are hydrogen transfer photo-radical initiators. Among them, BDI-3 showed the highest sensitivity, probably because of the long side chain, which provides more compatibility to PETA than BDI-1 and BDI-2.

Synthesis of Photo-Radical Initiators Containing Acrylate Group (BDI-4, BDI-5)

Introduction of vinyl groups to the photo-radical

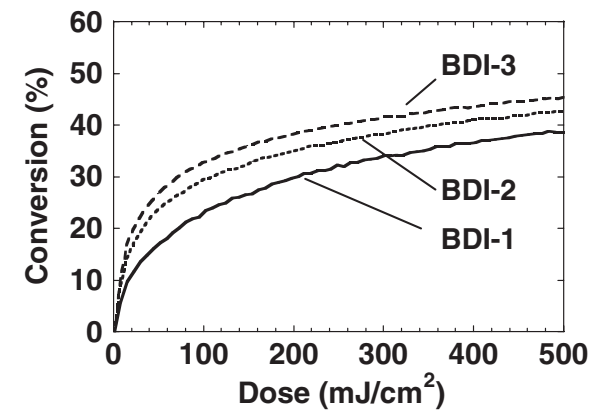

Figure 2. Conversion of vinyl group of the mixture containing PETA, TEA and BDI-1 BDI-3 (Lighting intensity of high-presser mercury-arc lamp: $55 \mathrm{~mW} / \mathrm{cm}^{2}$ )

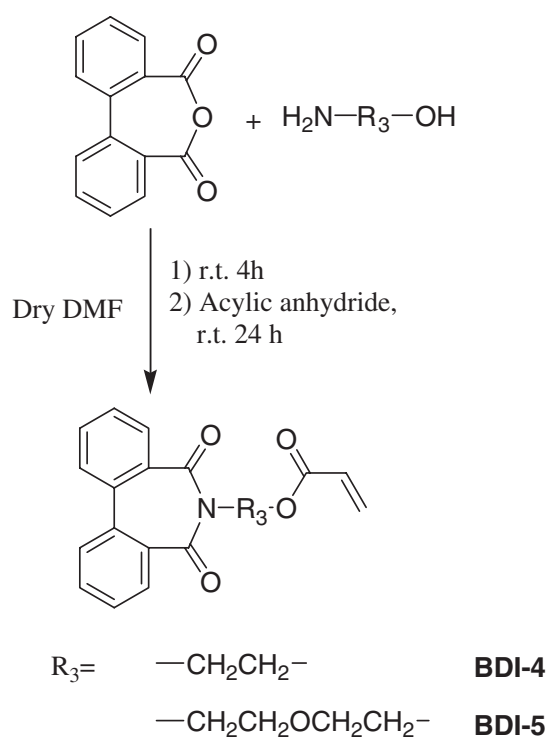

Scheme 4. Synthesis of BDI-4 and BDI-5.

initiator is effective to prevent the generation of the volatiles from coatings upon thermal treatment. An acrylate unit as the vinyl group was introduced into BDI to form a new low volatile photo-radical initiator. BDI moiety can be connected to a coating matrix via chemical bond during UV-exposure.

As a spacer between imide ring and acryloyl moiety, an ethyleneglycol unit, which was the most efficient spacer in a previous work, ${ }^{4}$ was selected. (Scheme 4) Acrylic anhydride was used to obtain BDI-4 and BDI-5, and acted as the condensation agent and introducing agent of acrylate group (Scheme 4). BDI-4 and BDI-5 were soluble in various organic solvents and acrylates compared to NI.

\section{Thermal Properties of BDI-4 and BDI-5}

The thermal properties of BDI-4 and BDI-5 are summarized in Table III. These compounds also showed high thermal stability. A 5\% weight loss temperature of BDI-5 was specifically high, because BDI-5 polymerized during the TGA measurement. 
Table III. Thermal properties of BDI-4 and BDI-5

\begin{tabular}{ccc}
\hline Photoinitiator & $\begin{array}{c}\text { Melting point } \\
\left({ }^{\circ} \mathrm{C}\right)\end{array}$ & $\begin{array}{c}\text { The temperature for } \\
5 \% \text { weight loss }{ }^{\mathrm{a}}\left({ }^{\circ} \mathrm{C}\right)\end{array}$ \\
\hline BDI-4 & 108 & 234 \\
BDI-5 & 51 & 351 \\
\hline
\end{tabular}

${ }^{\mathrm{a}}$ in nitrogen from TG-DTA at a heating rate of $10^{\circ} \mathrm{C} / \mathrm{min}$, ${ }^{b}$ liquid at $23^{\circ} \mathrm{C}$.

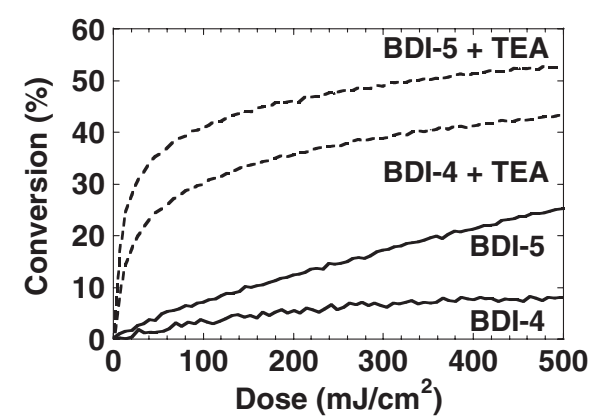

Figure 3. Conversion of vinyl group of the mixture containing PETA, TEA and BDI-4 BDI-5 (Lighting intensity of high-presser mercury-arc lamp: $55 \mathrm{~mW} / \mathrm{cm}^{2}$ )

\section{Photosensitivity of BDI-4 and BDI-5}

Figure 3 shows the decrease of the vinyl group in coatings containing BDI-4 or BDI-5 and PETA in the presence and absence of an equimolar amount of TEA. Both of BDI-4 and BDI-5 showed less efficiency on photoinitiation in the absence of TEA. On the contrary, the photosensitivity of both compounds was improved dramatically in the presence of TEA, and also was higher than BDI-1-BDI-3 without the acrylate group. Furthermore, BDI-5 showed higher sensitivity than BDI-4. From these results, the photosensitivity of BDI-4 and BDI-5 concerns the length of side-chain, and the acrylate group of the end of the side-chain influences on the initiation for the polymerization of PETA. The long side chain and acrylate group improve the compatibility between the BDI component and PETA, and the radical generation efficiency of BDI-5 increased.

\section{Probable Initiation Mechanism of BDI}

The probable initiation mechanism of BDI-5 is shown in Scheme 5. As the imide carbonyl group of BDI-5 will be an isolated carbonyl one, BDI-5 generates radicals by hydrogen abstraction via $n \pi^{*}$ triplet states as in the case of a radical generation by benzophenone with an hydrogen donor, where BDI-5 requires the hydrogen donor for the effective radical generation.

Comparison of Photosensitivity between BDI, BPA, and $\operatorname{Irg} 907$

The photosensitivity of BDI-5 with TEA was com-
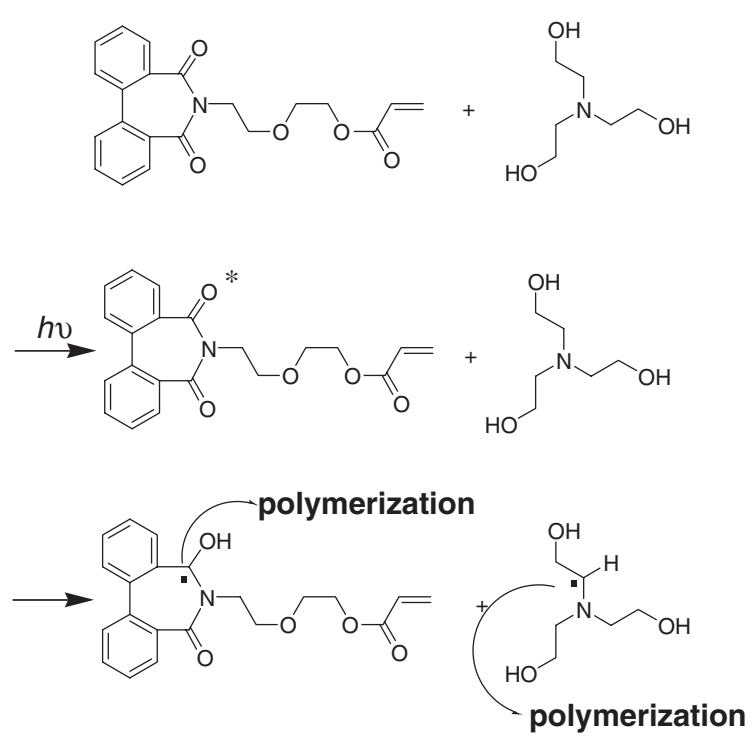

Scheme 5. Initiation mechanism of BDI-5.

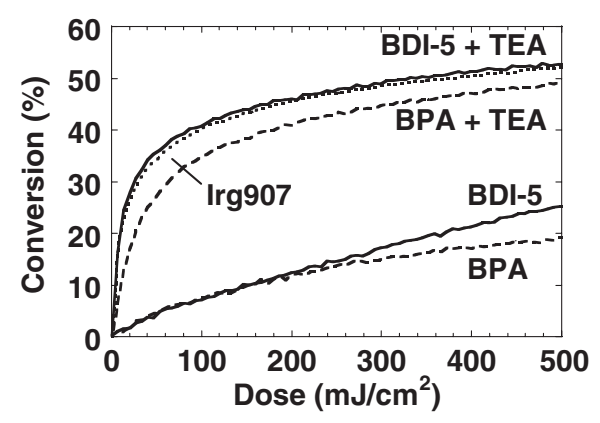

Figure 4. Conversion of vinyl group of the mixture containing PETA and BDI-5, BPA, and Irg907. (Lighting intensity of highpressure mercury-arc lamp: $55 \mathrm{~mW} / \mathrm{cm}^{2}$ )

pared to those of reported photo-radical initiators. The results are shown in Figure 4. The photosensitivity of BDI-5 is almost same to that of BPA. In the presence of TEA, BDI-5 showed higher sensitivity than BPA and almost same sensitivity to Irg907. In the case of the film containing BDI-5, the dose required to decrease vinyl groups over $40 \%$ is about $80 \mathrm{~mJ} / \mathrm{cm}^{2}$. On the other hand, that of BPA is $180 \mathrm{~mJ} / \mathrm{cm}^{2}$, which means the exposure time of BDI-5 is reduced to a half of BPA. From these results, BDI-5 with TEA can be used for practical application.

\section{Comparison of Transmittance of Films between BDI-5 and $\operatorname{Irg} 907$}

Transparency of coatings is the key issue for various applications. Thus, the transmittance of the films obtained from PETA and BDI-5 in the presence of TEA was examined. The solution was cast on the glass by spin coating and the film was cured with the exposed dose of $2 \mathrm{~J} / \mathrm{cm}^{2}$, where the molar ratio of PETA, BDI-5 and TEA was 17 to 1 to 1 . As the comparison, the film containing $\operatorname{Irg} 907$ was prepared 


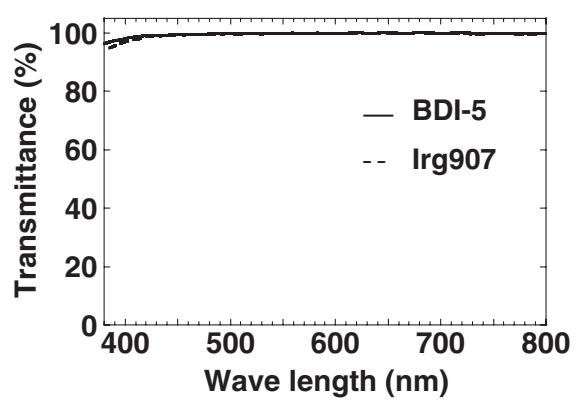

Figure 5. Transmittance of the film containing BDI-5 with TEA and Irg907 after UV-cure.

with the same procedure, where the molar ratio of PETA to $\operatorname{Irg} 907$ was 17 to 1 . The film thickness was $4.2 \mu \mathrm{m}$. Figure 5 shows the transmittance of the films containing BDI-5 with TEA and Irg907 in the range of $400-800 \mathrm{~nm}$, which indicates the film containing BDI-5 with TEA is very transparent $(97 \%)$ in the range of $500-800 \mathrm{~nm}$, which is comparable to that of the film containing $\operatorname{Irg} 907$.

\section{CONCLUSIONS}

BDI-1-BDI-3 were prepared from diphenic anhydride and primary amines followed by imidization, and investigated their thermal stability and photosensitivity using PETA as the matrix. BDI-1-BDI-3 showed high thermal stability over $220^{\circ} \mathrm{C}$ and high sensitivity in the presence of TEA as the proton donor. They acted as the hydrogen transfer type photo-initiator. Based on these findings, BDI-4 and BDI-5 having the acrylate unit were prepared. BDI-5 with TEA was the best photo-radical initiator for clear coatings because of its high photosensitivity comparable to that of Irg907 and high thermal stability over $300^{\circ} \mathrm{C}$. The coating films obtained by using BDI- 5 with TEA was very transparent in the range of $400-800 \mathrm{~nm}$. Thus, the newly developed BDI-5 and TEA system with high sensitivity can be used for practical clear coatings.

\section{REFERENCES}

1. J. V. Crivello and K. Dietliker, "Photoinitiators for Free Radical and Cationic and Anionic Photomolymerization," 2nd ed., Wiely, New York, 1998.

2. J.-P. Fouassier, "Photoinitiation and Photocurering," Hanser, New York, 1995.

3. T. B. Cavitt and S. Jonsson, J. Polym. Sci., Part A: Polym. Chem., 42, 4009 (2004).

4. K. Sakayori, Y. Shibasaki, and M. Ueda, J. Polym. Sci., Part A: Polym. Chem., 43, 5571 (2005).

5. Y. Kubo, T. Araki, and K. Maruyama, Chem. Lett., 1909 (1984).

6. Y. Kubo and K. Maruyama, Bull. Chem. Soc. Jpn., 58, 2863 (1985).

7. P. Caillet and J. Y. Le Marouille, Acta Crystallogr., Sect. B: Struct. Sci., 34, 175 (1978). 